\title{
Fungal Treatment Modifies Kraft Lignin for Lignin- and Cellulose-Based Carbon Fiber Precursors
}

\section{Mikkila, Joona}

2020-03-24

Mikkila , J , Trogen , M , Koivu , K A Y , Kontro , J , Kuuskeri , J , Maltari , R , Dekere , Z , Kemell , M , Makela , M R , Nousiainen, P A , Hummel , M , Sipila , J \& Hilden , K 2020 , ' Fungal Treatment Modifies Kraft Lignin for Lignin- and Cellulose-Based Carbon Fiber Precursors ' , ACS Omega , vol. 5 , no. 11 , pp. 6130-6140 . https://doi.org/10.1021/acsomega.0c00142

http://hdl.handle.net/10138/314167

https://doi.org/10.1021/acsomega.0c00142

cc_by

publishedVersion

Downloaded from Helda, University of Helsinki institutional repository.

This is an electronic reprint of the original article.

This reprint may differ from the original in pagination and typographic detail.

Please cite the original version. 


\title{
Fungal Treatment Modifies Kraft Lignin for Lignin- and Cellulose- Based Carbon Fiber Precursors
}

\author{
Joona Mikkilä,* Mikaela Trogen, Klaus A. Y. Koivu, Jussi Kontro, Jaana Kuuskeri, Riku Maltari, \\ Zane Dekere, Marianna Kemell, Miia R. Mäkelä, Paula A. Nousiainen, Michael Hummel, Jussi Sipilä, \\ and Kristiina Hildén
}

Cite This: ACS Omega 2020, 5, 6130-6140

Read Online

ACCESS | W Metrics \& More
ABSTRACT: The kraft lignin's low molecular weight and too high hydroxyl
content hinder its application in bio-based carbon fibers. In this study, we
were able to polymerize kraft lignin and reduce the amount of hydroxyl
groups by incubating it with the white-rot fungus Obba rivulosa. Enzymatic
radical oxidation reactions were hypothesized to induce condensation of
lignin, which increased the amount of aromatic rings connected by carbon-
carbon bonds. This modification is assumed to be beneficial when aiming for
graphite materials such as carbon fibers. Furthermore, the ratio of remaining
aliphatic hydroxyls to phenolic hydroxyls was increased, making the structure
more favorable for carbon fiber production. When the modified lignin was mixed together with cellulose, the mixture could be spun into intact precursor fibers by using dry-jet wet spinning. The modified lignin leaked less to the spin bath compared with the unmodified lignin starting material, making the recycling of spin-bath solvents easier. The stronger incorporation of modified lignin in the precursor fibers was confirmed by composition analysis, thermogravimetry, and mechanical testing. This work shows how white-rot fungal treatment can be used to modify the structure of lignin to be more favorable for the production of bio-based fiber materials.

\section{INTRODUCTION}

Environmental concerns such as reduction of carbon footprint set a demand for the development of more sustainable technologies and materials. One way to respond to environmental challenges is to use biorefinery side streams to develop cost-efficient and environmentally friendly processes for renewable production of chemicals, materials, fuels, and energy. ${ }^{1}$ Lignin is the second-most abundant biopolymer after cellulose, and due to its aromatic nature, it could be used to replace oil-based starting materials and chemicals. Different types of technical lignins have been produced mostly as side products of the pulp and paper industry. So far, they have been utilized only to a small extent in commercial applications such as production of vanillin ${ }^{2}$ and industrial binders. ${ }^{3}$ Nevertheless, the vast majority of the approximately 100 million tons of technical lignins produced annually is not refined into carbonsequestering products but mostly burned as a low-value fuel.

The interest of applying lignin in more sophisticated and higher value applications is growing. ${ }^{4}$ Lignins have shown great potential as a raw material, for example, in energy storage applications, ${ }^{5-7}$ carbon fibers, $^{8-10}$ and nanoparticles for drug delivery. ${ }^{11}$ Especially, the lignin-based carbon fibers have gained a lot of attention because lignins have a high carbon content (approximately 60\%), and they are rich in aromatic moieties, which are both desired features when aiming for carbon fibers with good mechanical properties. ${ }^{1,12}$ Lignin- based carbon fibers could represent more than $50 \%$ cheaper option than the current polyacrylonitrile (PAN)-based fibers ${ }^{13}$ and could be utilized in various applications with moderate strength requirements such as in light-weight composites for the automotive sector. ${ }^{14}$ The weight reduction of cars is urgently needed to comply with the EU emission target of $95 \mathrm{~g}$ $\mathrm{CO}_{2} / \mathrm{km}$ effective in 2021. ${ }^{15}$ Moreover, lignin-based carbon fibers have high electrochemical activity and serve as an excellent electrode material in the batteries and supercapacitors needed for the increasing electrification of transportation. ${ }^{16,17}$

Kraft lignins are side products of the kraft pulping process that is the principal method for the production of wood pulp today. These lignins comprise $90 \%$ of the annually produced technical lignins, and they have been studied as a starting material for carbon fiber production. ${ }^{18,19}$ However, the mechanical properties of fully lignin-based fibers do not meet the standards, which are required from the materials intended for the automotive industry. Lignin has also been combined with PAN to gain partially bio-based carbon fibers. ${ }^{20,21}$

Received: January 11, 2020

Accepted: February 28, 2020

Published: March 10, 2020 
Table 1. Proteins in the Secretome of $O$. rivulosa $a^{a}$

\begin{tabular}{|c|c|c|c|c|c|c|c|}
\hline protein ID & description of the function & score & coverage & \# proteins & \# unique peptides & \# peptides & \# PSMs \\
\hline 1045908601 & laminarinase & 5.95 & 6.31 & 1 & 2 & 2 & 4 \\
\hline 1045909454 & putative laminarinase & 7.34 & 6.31 & 1 & 2 & 2 & 3 \\
\hline 1045915360 & laccase 1 & 4.31 & 2.89 & 1 & 1 & 1 & 2 \\
\hline 1045918057 & hypothetical protein & 3.64 & 10.67 & 1 & 1 & 1 & 2 \\
\hline 1045916225 & glycoside hydrolase family 79 protein & 4.85 & 1.48 & 1 & 1 & 1 & 2 \\
\hline 1045912416 & manganese-dependent peroxidase & 1.92 & 4.12 & 1 & 2 & 2 & 2 \\
\hline 1045918856 & tRNA modification GTPase TrmE & 1.76 & 1.28 & 1 & 1 & 1 & 1 \\
\hline 1045917176 & hypothetical protein & 1.71 & 0.98 & 1 & 1 & 1 & 1 \\
\hline 1045915036 & $\alpha / \beta$-hydrolase & 1.76 & 1.94 & 1 & 1 & 1 & 1 \\
\hline 1045915029 & cellobiohydrolase II & 1.70 & 1.54 & 1 & 1 & 1 & 1 \\
\hline 1045914082 & FAD-binding domain-containing protein & 0.00 & 1.85 & 1 & 1 & 1 & 1 \\
\hline 1045913830 & glucoamylase & 0.00 & 1.22 & 2 & 1 & 1 & 1 \\
\hline 1045908639 & aspartic peptidase $\mathrm{A} 1$ & 1.89 & 2.19 & 1 & 1 & 1 & 1 \\
\hline
\end{tabular}

${ }^{a}$ Protein ID and description of the putative protein function correspond to the accession number and definition at the GenBank (www.ncbi.nlm. nih.gov). PSM, peptide spectral match.

Unfortunately, the mechanical properties of these fibers are not satisfying, and the cost of the final products is still highly dependent on the price of PAN. Several studies have shown that fractionation of technical lignins provides a way to gain starting materials with enhanced properties such as better spinnability, which result in higher-quality carbon fibers. ${ }^{12,22}$ Commercially available kraft lignin that has been fractionated using LignoBoost technology is less polydisperse and contains less impurities than traditional kraft lignin and therefore has potential in carbon fiber production. ${ }^{23,24}$ However, the previous attempts to produce carbon fibers from LignoBoosttype lignins have shown only preliminary prospects. ${ }^{25,26}$ Successful stabilization of purely lignin-based precursor fibers remains very challenging, which, in most cases, has lowered the quality of the final product. Recently, Byrne et al. have presented a new bicomponent dry-jet wet spinning method to resolve the issues encountered when trying to produce purely lignin-based fibers. ${ }^{27}$ They show that, by combining lignin with cellulose, stronger and faster stabilizing fibers are formed compared to fibers based on either of the components only.

To further enhance the properties of cellulose-lignin precursor fibers, the chemical properties of lignin could be tuned in a sustainable way by utilizing fungal enzymes. For example, laccases oxidize phenolic hydroxyl groups and have been reported to slightly depolymerize lignin, but the formed radicals preferably repolymerize rapidly, thus resulting in polymerization of lignin. ${ }^{28,29}$ Both increase of molecular weight and decrease of hydroxyl content have been suggested to be beneficial changes in the lignin structure when aiming for highquality carbon fibers. ${ }^{23}$ Radical polymerization causes also condensation of lignin. This increases the abundance of aromatic rings connected by carbon-carbon bonds that are the basis of the graphite structure in carbon fibers.

In nature, basidiomycete wood-decaying white-rot fungi are unique in their ability to degrade all the components of plant biomass. They secrete a set of enzymes to degrade and modify lignin and to get access to hemicelluloses and cellulose, which they use as carbon and energy sources. ${ }^{30}$ The basidiomycete fungus $\mathrm{Obba}$ rivulosa $^{31}$ is a rare wood-decaying white-rot species, which grows on softwood in northern temperate and boreal forests. In its natural environment, O. rivulosa degrades lignin by producing extracellular nonselective oxidative enzymes such as class II heme peroxidases and laccases, and therefore, it was chosen to modify softwood-derived kraft lignin.

In this study, we show that $O$. rivulosa was able to secrete an enzyme mixture with a high potential for lignin modification. We cultivated $O$. rivulosa on Lineo kraft lignin that has been produced using LignoBoost technology. O. rivulosa polymerized the lignin and concomitantly increased the level of condensation and decreased the abundance of hydroxyl groups, which are modifications that can enhance the quality of the resulting fibers. ${ }^{23,24}$ Our findings demonstrate that fungal treatment can be utilized for sustainable valorization of kraft lignin.

\section{RESULTS AND DISCUSSION}

Secretome Analysis. The secretome-that is, the extracellular enzymes-of $O$. rivulosa from the 1 week lignin cultivation showed 15 detected proteins (Table 1). The majority were carbohydrate active enzymes (CAZy) belonging either to the glycoside hydrolase $(\mathrm{GH})$, carbohydrate esterase (CE), or auxiliary activity (AA) families (www.cazy.org). Laccase 1 (Lcc1, family AA1) and Mn-peroxidase (MnP, family AA2) were the identified lignin-modifying oxidoreductases. Previously, laccase- and oxidoreductase-containing secretomes have been shown to cause both depolymerization and repolymerization of lignin substrates. ${ }^{32}$ Laccase activity in the secretome of $O$. rivulosa was $1.3 \mu$ kat $\mathrm{L}^{-1}$ when 2,6-DMP was used as a substrate. The $\mathrm{MnP}$ detected in the secretome may also have a role in lignin modification. However, the measured $\mathrm{MnP}$ activity in the culture medium was under reliable detection limit, and therefore, we suggest that only laccase contributed to lignin modification. Furthermore, the $\mathrm{MnP}$-promoted reactions resemble laccase-catalyzed reactions in lignin, modifying basically only phenolic structures in our reaction conditions. ${ }^{33}$ Lccl was the only laccase detected from $O$. rivulosa grown on spruce wood (Marinovic et al., unpublished), and it has been also purified from spruce wood chip cultivations, ${ }^{34}$ suggesting an important role for this isoenzyme in lignin modification. In addition, enzymes from families GH6, GH15, GH16, GH35, GH79, and CE16 were detected in the secretome. 
Lignin Analysis. Untreated kraft lignin, reference lignin incubated without fungus, and lignin incubated with O. rivulosa were referred as $\mathrm{KL}, \mathrm{RL}$, and $\mathrm{OL}$, respectively. The molecular weight distributions of all samples were analyzed by gel permeation chromatography (GPC) (Figure 1). The $M_{\mathrm{n}} / M_{\mathrm{w}}$

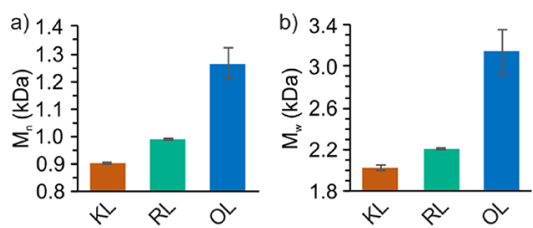

Figure 1. GPC results showing the changes in (a) $M_{\mathrm{n}}$ and (b) $M_{\mathrm{w}}$ of fungal-treated lignin. KL, RL, and OL stand for untreated lignin, reference lignin incubated without fungus, and lignin incubated with O. rivulosa, respectively. Vertical error bars represent standard deviations of three replicate experiments.

values of $\mathrm{KL}, \mathrm{RL}$, and OL were measured to be $900 / 2020$, $990 / 2200$, and $1260 / 3140 \mathrm{Da}$, respectively. When compared to untreated lignin $(\mathrm{KL})$, the molecular weight distributions of fungal-treated lignin (OL) increased by $40-55 \%$. The small $9-10 \%$ increase in molecular weights of reference samples
(RL) was most likely due to the chemical and structural heterogeneity of kraft lignin. ${ }^{35}$ A small part of lignin dissolved in to the solution and was not collected in filtration after the incubations. This residual lignin was observed as a light brown color in the filtrates, and it was removed before analyzing the secretome (see the Supporting Information). Incubation did not remarkably affect the polydispersity of lignin; thus, the calculated PDIs of all samples were between 2.22 and 2.49. Taken together, GPC results show that the enzymes secreted by $O$. rivulosa cause polymerization of lignin. In contrast, the white-rot fungal species Phanerochaete chrysosporium has been shown to catalyze both degradation and condensation of synthetic lignin depending on the incubation time of the cultivations. ${ }^{36}$

The relative abundance of lignin interunit bonds and structural units between different samples was studied by ${ }^{1} \mathrm{H}-{ }^{13} \mathrm{C}$ heteronuclear single quantum coherence nuclear magnetic resonance spectroscopy (HSQC NMR) (Figure 2). Interpretations were done according to the literature (see Experimental Section), and distinct peaks were integrated (Table S2, Supporting Information). The spectra measured from KL (Figure S1, Supporting Information) and RL (Figure $2 \mathrm{a}-\mathrm{c})$ were very similar, and no remarkable modifications

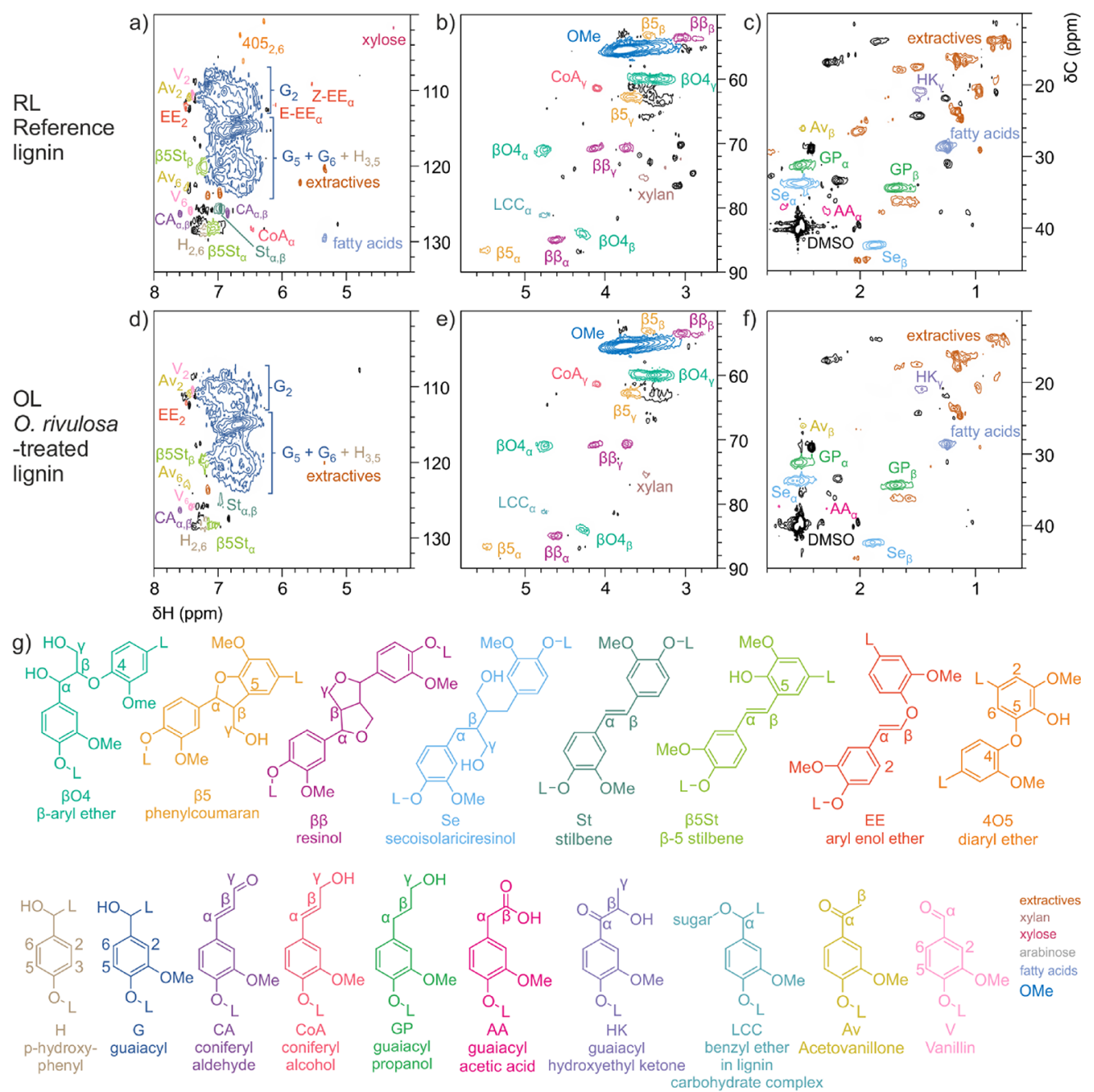

Figure 2. Sliced HSQC spectra of $(\mathrm{a}-\mathrm{c})$ reference lignin $\mathrm{RL}$ and $(\mathrm{d}-\mathrm{f})$ lignin incubated with $\mathrm{O}$. rivulosa OL. Color-coded abbreviations correlate to $(\mathrm{g})$ the different lignin interunit bonds and structural units, and the interpretations were done according to the literature (see Experimental Section). 


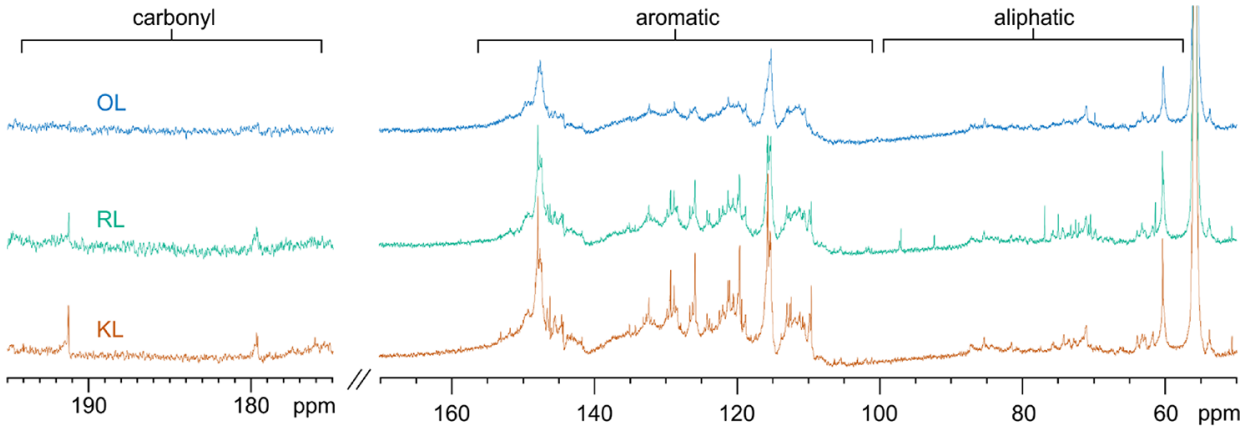

Figure $3 .{ }^{13} \mathrm{C}$ NMR spectrum of fungal-treated lignin $(\mathrm{OL})$, reference lignin $(\mathrm{RL})$, and untreated lignin $(\mathrm{KL})$.

Table 2. Total Hydroxyl Contents ( $\mathrm{mmol} \mathrm{g}^{-1}$ Lignin) of Untreated Lignin (KL), Reference Lignin (RL), and Fungal-Treated Lignin (OL) Determined by Quantitative ${ }^{31} \mathrm{P}$ NMR

\begin{tabular}{cccccccc} 
sample & aliphatic $\mathrm{OH}$ & C5-substituted phenolic OH & G-OH & H-OH & COOH & total OH content $\left(\mathrm{mmol} \mathrm{g}^{-1}\right.$ lignin) & aliphatic OH/phenolic OH \\
KL & 2.02 & 1.80 & 1.94 & 0.19 & 0.45 & 6.40 \\
RL & 1.91 & 1.58 & 1.78 & 0.20 & 0.49 & 5.96 \\
OL & 1.60 & 1.42 & 0.07 & 0.26 & 4.51 \\
\hline
\end{tabular}

could be observed in the lignin structure. The only noticeable differences in $\mathrm{RL}$ were the appearance of residual nondeuterated DMSO, succinic acid $(\delta \mathrm{C} / \delta \mathrm{H} 28.8 / 2.4)$, and carbohydrates $(\delta \mathrm{C} / \delta \mathrm{H} 68-77 / 2.9-3.6)$ originating from the culture medium. In the spectra of OL (Figure $2 \mathrm{~d}-\mathrm{f}$ ), no sign of carbohydrates from the culture medium was detected, and the signals of xylose and xylan originating from kraft lignin were decreased as well. This indicates that the fungus consumed the available carbohydrates. The signals of extractives at the aliphatic region (Figure $2 \mathrm{c}, \mathrm{f}$ ) and at the aromatic region (Figure 2a,d) were smaller in the spectra of OL than in the spectra of RL. Incubation together with O. rivulosa seemed to induce condensation of the lignin detected as a decrease of $G_{2}$, $\mathrm{G}_{5}$ and $\mathrm{G}_{6}$ signals at the aromatic region. This finding is in good agreement with the previously discussed GPC results and the work of Zhao et al. where kraft lignin was treated with laccase. $^{37}$

In addition, fungal treatment of lignin removed or decreased the aromatic area signals coming from aryl enol ether (EE), stilbene $(\mathrm{St})$, and $\beta-5$ stilbene $(\beta 5 \mathrm{St})$ interunit bonds and coniferyl aldehyde (CA) and coniferyl alcohol (CoA) end groups. This suggests that enzymatic mixture secreted by $O$. rivulosa modified the double bonds between $\alpha$ - and $\beta$-carbons. Moreover, all the signals coming from diaryl ether $\left(4 \mathrm{OS}_{2,6}\right)$ units found in both $\mathrm{KL}$ and $\mathrm{RL}$ were not present after fungal treatment. At the aliphatic area (Figure $2 \mathrm{c}, \mathrm{f}$ ), the guaiacyl hydroxyethyl ketone $\left(\mathrm{HK}_{\gamma}\right)$ and guaiacyl acetic acid $\left(\mathrm{AA}_{\alpha}\right)$ lignin unit signals diminished clearly, and also, several unidentified peaks either disappeared or decreased.

The changes in the chemical structure of lignin were further studied by using ${ }^{13} \mathrm{C}$ NMR (Figure 3 ). Carbohydrates from the culture medium were visible at the aliphatic side-chain region ( $\delta$ C $68-77$ and 92-98) in the spectrum of RL. The broadening of the peaks at the aromatic region $(\delta \mathrm{C} 108-$ $155)$ in the spectrum of $\mathrm{OL}$ is a clear indication of polymerization and condensation by fungal treatment. The uronic acid carbonyl group signal at $179.7 \mathrm{ppm}$ and $\mathrm{C} \alpha$ carbonyl group signal at $191.3 \mathrm{ppm}$ were visible in the spectra of KL and RL but not in the spectrum of OL. These findings support the assumption that enzyme activities produced by the fungus remove carbohydrates and polymerize lignin.
The changes in the hydroxyl contents were analyzed using the quantitative ${ }^{31} \mathrm{P}$ NMR technique (Table 2). The total hydroxyl contents for $\mathrm{KL}, \mathrm{RL}$, and $\mathrm{OL}$ were 6.40, 5.96, and 4.51 , respectively. The decrease in total hydroxyl content is a sign of oxidation and condensation, as is also the broadening of signals in the spectrum of fungal-treated samples (data not shown here). Moreover, the ratio of aliphatic hydroxyls and phenolic hydroxyls increased in the case of OL, resulting in theoretically more promising material for carbon fiber production, due to enhanced intermolecular interactions. ${ }^{21}$ More specifically, the more equal amount of aliphatic and phenolic hydroxyls has been proposed to result in multiple intermolecular hydrogen bonding between lignin molecules, which can align the lignin molecules and enhance their interaction with the quest polymers. At the carbonization step, these better organized structures could result in more intact layers of graphene.

Fiber and Material Analysis. Highly condensed lignin would represent an excellent precursor material to obtain a carbon matrix with extended graphene layers and high orientation upon pyrolysis. This would lead to enhanced mechanical properties of the resulting carbon fibers. ${ }^{12}$ However, classical melt processing of high-molecular-weight lignin is not possible as the glass transition temperature of such lignin samples is higher than the decomposition temperature. Plasticizing chemical modifications is required to obtain a thermoplastic biopolymer. To bypass this problem, lignin can be dissolved in direct solvents along with cellulose as the rheological lead polymer. The viscoelastic properties of the resulting solution are mostly determined by the carbohydrate fraction, allowing it to blend in any lignin species. ${ }^{38}$ In this study, unmodified and fungal-treated lignins were mixed with a commercial hardwood cellulose pulp, dissolved in the ionic liquid 1,5-diazabicyclo[4.3.0]non-5-ene acetate ([DBNH]$\mathrm{OAc}$ ), and spun into mixed-polymer precursor fibers using a dry-jet wet spinning unit. ${ }^{38}$ To prepare $100 \mathrm{~g}$ of OL for fiber spinning, we carried out over 400 repetitions in the same way as the three original OL repetitions. We compared the OLbased fibers to fibers prepared using untreated KL because no remarkable changes had been noticed in the structure of $R L$ that had been incubated without fungus. 
The ratios of lignin, cellulose, and hemicellulose content in the spun precursor fibers were determined by carbohydrate analysis (Table 3). Both fibers spun using the KL and OL had

Table 3. Carbohydrate and Lignin Analysis of Untreated Lignin (KL), Fungal-Treated Lignin (OL), and Precursor Fibers Prepared Together with Cellulose Pulp

$\begin{array}{lccc}\text { raw material } & \text { lignin (\%) } & \text { cellulose (\%) } & \text { hemicellulose (\%) } \\ \text { cellulose pulp } & 0.6 & 91.7 & 7.7 \\ \text { KL } & 96.3 & 0.3 & 3.4 \\ \text { OL } & 96.3 & 0.6 & 3.1 \\ \text { precursor fiber } & \text { lignin (\%) } & \text { cellulose (\%) } & \text { hemicellulose (\%) } \\ \text { cellulose-KL }^{\text {K }} & 25.5 & 69.4 & 5.1 \\ \text { theoretical }^{a} & 29.3 & 64.3 & 6.4 \\ \text { cellulose-OL }^{a} & 27.2 & 67.8 & 5.0 \\ \text { theoretical }^{a} & 29.3 & 64.4 & 6.3 \\ { }^{a} \text { Calculated from }^{2} \text { raw materials. } & & \end{array}$

a theoretical lignin content of $29.3 \%$. However, the measured lignin percentages for KL- and OL-based fibers were 25.5 and $27.2 \%$, respectively. Also, the portions of cellulose and hemicelluloses were measured to be closer to the theoretical value in the case of OL than in the case of KL. Only a small portion of OL was lost in the spin bath, which was also visible through discoloration of water in the coagulation bath. More precisely, when the precursor fibers were spun using untreated lignin, the color of the spin bath turned more brownish than when using OL. This is an important aspect when considering the recyclability of the solvents, which is an essential factor for the economic viability of the processes.

The thermal properties of lignins and precursor fibers were analyzed using thermogravimetric analysis (TGA) and differential scanning calorimetry (DSC) (Figure $4 a-c$ ) and are reported in Table 4 . In the case of the precursor fibers, the measurements were performed on draw ratio 3 (DR3) and DR6 fibers; thus, any effect of thickness appears at the range of these DRs. The TGA thermal degradation data and the first derivative of TGA curve (DTG) for KL, RL, and OL are presented in Figure 4a. KL had the highest stability with the decomposition temperature (onset) at $323{ }^{\circ} \mathrm{C}$. $\mathrm{RL}$ had $13{ }^{\circ} \mathrm{C}$ and OL $22{ }^{\circ} \mathrm{C}$ lower onset temperature. The residual masses at $790{ }^{\circ} \mathrm{C}$ were between 42 and 46 wt \%. KL had the lowest residual mass of $42.1 \mathrm{wt} \%$, whereas OL had the highest residual mass of $46.1 \mathrm{wt} \%$. Increased residual mass can be due to a more condensed and polymerized lignin structure. ${ }^{39}$ The peaks in the DTG curves (Figure 4a, inset) indicate the highest decomposition rate, which were in line with the decomposition temperatures: $\mathrm{KL}$ at $400{ }^{\circ} \mathrm{C}, \mathrm{RL}$ at $392{ }^{\circ} \mathrm{C}$, and $\mathrm{OL}$ at $380{ }^{\circ} \mathrm{C}$.
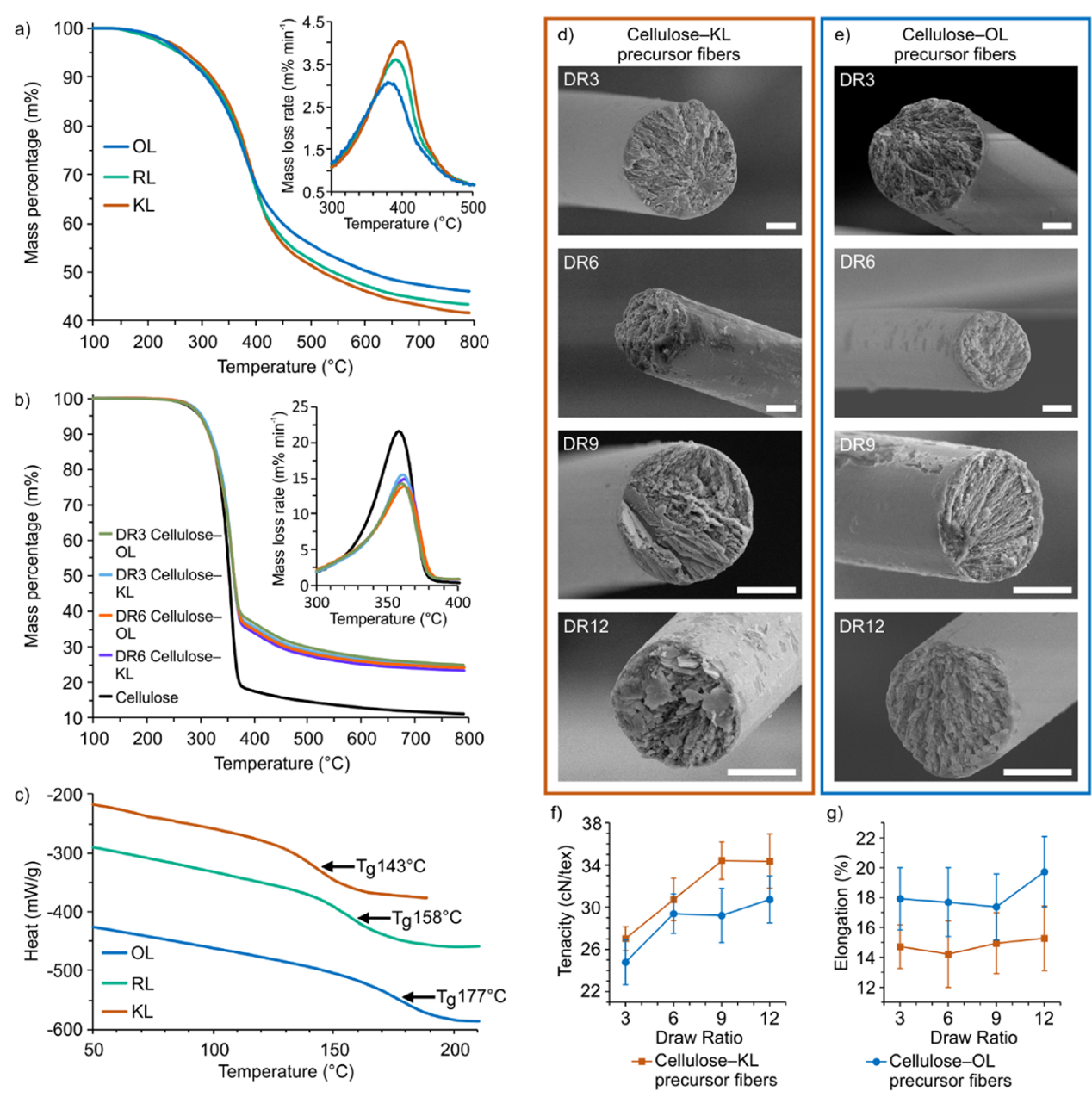

Figure 4. (a) TGA and DTG data (inset) measured from lignin samples. (b) TGA and DTG data (inset) measured from cellulose pulp and precursor fibers with DR3 and DR6. (c) DSC chart of lignin samples. SEM images from the cross sections of (d) cellulose-KL and (e) celluloseOL precursor fibers. Scale bar in each SEM image is $5 \mu \mathrm{m}$. (f) Tenacity and (g) elongation of the precursor fibers. 
Table 4. Thermal Data from TGA and DSC Measurements

\begin{tabular}{|c|c|c|c|c|c|c|}
\hline sample & $\begin{array}{l}\text { onset } \\
\left({ }^{\circ} \mathrm{C}\right)\end{array}$ & $\begin{array}{c}\text { residual mass by TGA }\left(790{ }^{\circ} \mathrm{C}\right) \\
\text { (wt \%) }\end{array}$ & $\begin{array}{l}\text { residual mass by calculation } \\
\text { (wt \%) }\end{array}$ & $\begin{array}{l}\text { peak mass loss temperature } \\
\qquad\left({ }^{\circ} \mathrm{C}\right)\end{array}$ & $\begin{array}{c}T_{\mathrm{g}} \\
\left({ }^{\circ} \mathrm{C}\right)\end{array}$ & $\begin{array}{l}\Delta T_{\mathrm{g}} \\
\left({ }^{\circ} \mathrm{C}\right)\end{array}$ \\
\hline $\mathrm{KL}$ & 323 & 42.1 & & 400 & 143 & \\
\hline $\mathrm{RL}$ & 310 & 43.4 & & 392 & 158 & +15 \\
\hline OL & 301 & 46.1 & & 380 & 177 & +34 \\
\hline cellulose pulp & 332 & 11.2 & & 358 & & \\
\hline DR6 cellulose-KL & 330 & 23.3 & 19.1 & 362 & & \\
\hline DR3 cellulose-KL & 332 & 24.4 & 19.1 & 361 & & \\
\hline DR6 cellulose-OL & 328 & 24.1 & 20.7 & 362 & & \\
\hline DR3 cellulose-OL & 329 & 24.9 & 20.7 & 361 & & \\
\hline
\end{tabular}

The TGA curves for cellulose pulp and precursor fibers are displayed in Figure $4 \mathrm{~b}$. The decomposition onset temperatures of OL-containing precursor fibers were $3-4{ }^{\circ} \mathrm{C}$ lower than that of cellulose pulp (onset temperature, $332{ }^{\circ} \mathrm{C}$ ), which is explained by the $31{ }^{\circ} \mathrm{C}$ lower onset temperature of pure OL lignin (Table 4). In the case of KL-containing fibers, the onset temperatures were $0-2{ }^{\circ} \mathrm{C}$ lower than the onset of cellulose pulp. Interestingly, the onset temperatures of both OLcellulose and $\mathrm{KL}$-cellulose fibers are higher when compared to organosolv-cellulose pulp ${ }^{27}$ or PAN-alkali kraft fibers. ${ }^{23}$ This provides more flexibility for the stabilization of the precursor fibers. The residual mass (at $790{ }^{\circ} \mathrm{C}$ ) of cellulose pulp was 11.2 wt $\%$, whereas precursor fibers had residual masses between 23.3 and 24.9 wt \%. As composites, the fibers' residual masses could also be calculated, and for example, for DR6 KL fibers, the calculated residual mass is $0.255 \times 42.1 \mathrm{wt} \%+0.745 \times$ 11.2 wt $\%=19.1 \mathrm{wt} \%$, which is $4.2 \mathrm{wt} \%$ lower than the measured residual mass. This suggests that the composite interactions affect the thermal properties of the fibers. Overall, it seems that lignin is responsible for most of the increase in the residual masses of the precursor fibers and composite interactions make up for the remaining 3.4-5.3 wt \% increase. The DTG curves for cellulose pulp and the cellulose-lignin fibers are shown in the inset of Figure $4 \mathrm{~b}$. The maximum decomposition rates of cellulose pulp, DR3 fibers, and DR6 fibers were at 358,361 , and $362{ }^{\circ} \mathrm{C}$, respectively. The decomposition of cellulose pulp slows down at temperatures above $380{ }^{\circ} \mathrm{C}$, while the fibers continue with further slow decomposition between 400 and $470{ }^{\circ} \mathrm{C}$ (data not shown).

The glass transition temperatures $\left(T_{\mathrm{g}}\right.$ 's) of the lignin samples were measured using DSC (Figure $4 c$ ). KL and RL had $T_{\mathrm{g}}$ values of 143 and $158{ }^{\circ} \mathrm{C}$, respectively. The $15{ }^{\circ} \mathrm{C}$ increase supports further the previously discussed finding that a small part of the lignin stayed in the solution when lignin was collected after the incubation, and most likely, the higher molecular weight and structural rigidity of the collected lignin result in higher $T_{\mathrm{g}}{ }^{40,41}$ The OL had a $T_{\mathrm{g}}$ of $177^{\circ} \mathrm{C}$, which is $19{ }^{\circ} \mathrm{C}$ higher than that of $\mathrm{RL}$ and $34^{\circ} \mathrm{C}$ higher than that of $\mathrm{KL}$. These results indicate that the enzyme mixture produced by $O$. rivulosa caused significant condensation of lignin and the phenyl moieties. Cellulose pulp and the precursor fibers did not show any glass transition between 20 and $260{ }^{\circ} \mathrm{C}$ in any heating or cooling cycle. The lignin content in the fibers is only $25-28 \%$, and it seems to be so well incorporated that neither pure lignin nor the composite polymer matrix gave rise to a detectable $T_{\mathrm{g}}$. Above $260{ }^{\circ} \mathrm{C}$, cellulose pulp and the fibers started to decompose in a manner that is unfit for DSC measurements.

The morphology of the precursor fibers was analyzed by scanning electron microscopy (SEM) (Figure 4d,e). All fibers had a circular cross section, smooth fiber surface, and a fibrillar body. These are typical characteristics for Lyocell-type fibers. $^{42,43}$ The round cross section with a very thin skin surrounding the filament is due to the postulated spinodal decomposition during the coagulation process. ${ }^{44}$ The decrease in diameter with increasing DR is clearly visible in Figure 4d,e. Nonetheless, the overall shape of the fibers does not change much. The bundle-like arrangement of the cellulose microfibrils reflects the orientation of the cellulose parallel to the fiber axis. It is caused, to some extent, by the shear forces in the spin capillary, but in particular, in dry-jet wet spun fibers, the orientation is mostly induced by the filament draw. At higher DRs, it seems that the fibers form partially two phases. It is possible that lignin as a planar polymer of substantially lower hydrophilicity phase-separates from the carbohydrate matrix during coagulation in water, forming microdomains embedded in the fiber body. This is currently investigated in more detail and will be reported in due time.

The mechanical properties of the precursor fibers were measured using a single-fiber tester. The tenacity and elongation of the precursor fibers at different DRs are shown in Figure 4f,g. The increase in DR promotes the longitudinal orientation of the cellulose polymer chains, which is reflected in the increasing tenacity. Concomitantly, the crystallinity of the cellulosic part in the fibers is getting higher, which makes the fiber stiffer and decreases the elongation. However, in both cases of lignin-cellulose fibers, the elongation was mostly independent from the DR. This is attributed to the lignin moieties, acting as a softener within the cellulose matrix. The tenacity is slightly lower and the elongation is higher for the fibers with the fungal-treated lignin (OL). Less lignin was lost during the spinning process when using the OL, making the lignin content higher in the final precursor fibers compared to the fibers made with KL lignin (Table 3). Ma et al. also reported that an increase in lignin content leads to a softening effect, resulting in lower tenacity and higher elongation. ${ }^{38,45}$

At DR 12, the tenacity was $30.7 \pm 2.2 \mathrm{cN} /$ tex with the $\mathrm{OL}$ and $34.4 \pm 2.6 \mathrm{cN} /$ tex with $\mathrm{KL}$. The tenacity values are in the same order as for fibers with beech organosolv lignin. Ma and co-workers reported a tenacity value of $30.1 \pm 3.6 \mathrm{cN} /$ tex (at DR 12.4) for a fiber containing eucalyptus PHK pulp and organosolv beech lignin $(70: 30){ }^{38}$

Despite the minor decrease in tensile strength, both the carbohydrate fraction and the lignin moieties are still highly orientated in the longitudinal direction. This promotes the formation of a carbon matrix with higher-order structure upon pyrolysis, as observed for both PAN- and bio-based carbon fibers. ${ }^{46}$ In addition, the circular cross section will allow for more uniform carbonization, minimizing possible radial gradients and often observed skin-core formation. ${ }^{12}$ In the 
future, we will study further the carbonization and properties of carbon fibers based on modified lignin and cellulose using a continuous carbonization line in which tension during the heating phases can be controlled accurately. This kind of fiber could replace the expensive and unsustainably produced PANbased carbon fibers or find use in battery electrodes and supercapacitors.

\section{CONCLUSIONS}

The enzymes produced by $O$. rivulosa catalyzed most likely oxidative radical coupling reactions, resulting in a more polymerized and condensed structure of Lineo kraft lignin. The ratio of aliphatic to phenolic hydroxyls of lignins increased, while the total hydroxyl content decreased. These modifications make the fungal-treated lignin a more promising material for carbon fiber production.

Precursor fibers spun from the fungal-treated lignin and cellulose pulp retained the lignin almost entirely in fiber unlike the unmodified lignin. The better lignin incorporation enables solvent recycling and improves the overall economic feasibility of the process. Clear polymer interactions in the precursor fibers affected the fibers' mechanical properties and their thermal behavior during pyrolysis. The carbon yield upon carbonization of the composite precursor fibers was notably increased. All these desired properties indicate that fungal treatment of kraft lignin results in a better starting material for precursor fibers.

\section{EXPERIMENTAL SECTION}

Materials. All chemicals were purchased from commercial suppliers and utilized without any further purifications. Lineo softwood kraft lignin was received from the Stora Enso Sunila Mill located in Kotka, Finland, and it was tyndallized before use in the experiments. Tyndallization did not modify the chemical structure of the KL, which was verified by GPC, PyGC-MS, HSQC NMR, (Figures S2 and S3) and TGA (Figure S4). Enocell Speciality Cellulose was received from Stora Enso Enocell Mill in Finland. The cellulose was received as pulp sheets and ground to a fine powder in a Wiley mill before use.

Fungal Strain and Cultivation Conditions. The white rot fungus O. rivulosa (FBCC939; syn. Physisporinus rivulosus) was obtained from the HAMBI Fungal Biotechnology Culture Collection, University of Helsinki, Finland (fbcc@helsinki.fi). The fungus was maintained on $2 \%(\mathrm{w} / \mathrm{v})$ malt extract agar plates and precultivated on low nitrogen $(2 \mathrm{mM})$-asparagine $(0.52 \mathrm{mM})$-succinate $(10 \mathrm{mM})-(\mathrm{LN}-\mathrm{AS})$ (modified from Hatakka and Uusi-Rauva $)^{47}$ minimal medium agar plates supplemented with $10 \%(\mathrm{w} / \mathrm{v})$ tyndallized lignin and $1 \%$ glucose at $28{ }^{\circ} \mathrm{C}$ in the dark for 1 week. Twenty myceliacovered agar plugs $(\varnothing 0.5 \mathrm{~cm})$ from the lignin plates were transferred in $50 \mathrm{~mL}$ of LN-AS supplemented with $0.2 \mathrm{~g}$ of tyndallized lignin and $2 \%$ DMSO to improve solubility of lignin to increase the enzymatic reaction rate. ${ }^{48}$ The $\mathrm{pH}$ was adjusted to 6.0. The cultivations were incubated at $+28{ }^{\circ} \mathrm{C}$ with $60 \mathrm{rpm}$ agitation for 1 week. After cultivation, agar plugs and mycelia were removed from cultivation media with a sieve. Lignin was collected by using vacuum filtration and Whatman glass microfiber filters (GF/CTM; diameter, $70 \mathrm{~mm}$ ). Collected lignin was dried under air flow at room temperature before analyzing it. All cultivations were performed in triplicate. Reference lignin incubations in a culture medium without fungus were also performed in triplicate. To confirm that the isolated lignin did not contain remarkable amounts of fungal biomass, we analyzed the amount of nitrogen in the untreated kraft lingin, reference lignin, and fungal-treated lignin. The percentage of nitrogen was $0.05 \pm 0.01 \%$ in all samples. The elemental analysis measurements were performed on an Elementar Analysensysteme (HANAU) model vario MICRO cube, operated in CHNS mode. Nitrogen was detected as a $\mathrm{N}_{2}$ gas with a thermal conductivity detector (TCD) and $\mathrm{He}$ as a carrier gas.

Secretome Analysis and Enzyme Activity Measurements. Twenty milliliters of filtrate from each cultivation was processed for proteomic studies. $\mathrm{NaCl}(2.22 \mathrm{~mL} ; 5 \mathrm{M})$ was added to increase the $\mathrm{NaCl}$ concentration to $0.5 \mathrm{M}$. The $\mathrm{pH}$ was adjusted to 3.5 by using $1 \mathrm{M} \mathrm{HCl}$. Solutions were centrifuged with Thermo Scientific SL 16R centrifuge $\left(22^{\circ} \mathrm{C}\right.$, $4000 \mathrm{rpm}, 40 \mathrm{~min}$ ). Supernatants were collected and tiny residual lignin pellets stayed in the tubes. The $\mathrm{pH}$ of the collected supernatants was increased to $\mathrm{pH} 5$ by adding $1 \mathrm{M}$ $\mathrm{NaOH}$. The supernatants were concentrated by using Amicon ultrafiltration units (Millipore) with 10,000 NMWL polyethersulfone membrane (Sartorius, Germany) (8000 g, $15 \mathrm{~min}$, $\left.4{ }^{\circ} \mathrm{C}\right)$.

Cysteine bonds of the concentrated proteins were reduced with $0.05 \mathrm{M}$ TCEP [(tris(2-carboxyethol)phosphine hydrochloride salt (Sigma-Aldrich, USA)] for $20 \mathrm{~min}$ at $37^{\circ} \mathrm{C}$ and alkylated with $0.15 \mathrm{M}$ iodoacetamide (Fluka, Sigma-Aldrich, USA) at room temperature. Samples were digested overnight at $37{ }^{\circ} \mathrm{C}$ by adding $1 \mu \mathrm{g}$ of trypsin (Promega). Digested peptides were quenched with $10 \%$ trifluoroacetic acid (TFA) and purified with C18 microspin columns (Harvard Apparatus, USA), eluting the samples to $0.1 \%$ TFA in $50 \%$ acetonitrile $(\mathrm{ACN})$. The dried peptides were reconstituted in $30 \mu \mathrm{L}$ of $0.1 \%$ TFA in $1 \%$ ACN (buffer A).

Liquid chromatography coupled to tandem mass spectrometry (LC-MS/MS) analysis was carried out on an EASYnLC1000 (Thermo Fisher Scientific, Germany) connected to a Q Exactive hybrid mass spectrometer (Thermo Fisher Scientific, Germany) with a nanoelectrospray ion source (Thermo Fisher Scientific, Germany). The LC-MS/MS samples were separated using a two-column setup consisting of a $2 \mathrm{~cm}$ C18-Pepmap trap column (Thermo Fisher Scientific, Germany), followed by $15 \mathrm{~cm}$ C18-Pepmap analytical column (Thermo Fisher Scientific, Germany). The linear separation gradient consisted of $5 \%$ buffer B in 5 min, 35\% buffer B in 20 min, $80 \%$ buffer B in $5 \mathrm{~min}$, and $100 \%$ buffer B in 10 min at a flow rate of $0.3 \mu \mathrm{L} \mathrm{min} \mathrm{m}^{-1}$ (buffer A: $0.1 \%$ TFA in $1 \%$ acetonitrile; buffer B: $0.1 \%$ TFA acid in $98 \%$ acetonitrile). Six microliters of the sample was injected per LC-MS/MS run and analyzed. Full MS scan was acquired with a resolution of 70,000 at a normal mass range in the Orbitrap analyzer; the method was set to fragment the 10 most intense precursor ions with HCD. Data was acquired using LTQ Tune software.

Acquired MS2 scans were searched against in-house protein database including the predicted proteins obtained from the $O$. rivulosa genome ${ }^{49}$ using the Sequest search algorithms in Thermo Proteome Discoverer. The allowed mass error for the precursor ions was $15 \mathrm{ppm}$ and for the fragment in $0.05 \mathrm{Da}$. A static residue modification parameter was set for carbamidomethyl (+57.021 Da (C)) of the cysteine residue. Methionine oxidation was set as dynamic modification $(+15.995 \mathrm{Da}(\mathrm{M}))$. Only full-tryptic peptides with a maximum of one missed cleavage were considered. The secretome analyses were 
performed by the Proteomics Unit, Institute of Biotechnology, University of Helsinki, Finland.

Laccase activity measurements were performed using a Tecan Infinite M200 plate reader (Tecan, Austria). Activity was determined spectrophotometrically at $476 \mathrm{~nm}$ by detecting the oxidation of 2,6-dimethoxyphenol (2,6-DMP; Sigma Aldrich) at $\mathrm{pH} \mathrm{6,} \mathrm{which} \mathrm{was} \mathrm{in} \mathrm{line} \mathrm{with} \mathrm{the} \mathrm{cultivation}$ conditions, in malonate buffer. ${ }^{50} \mathrm{MnP}$ activity was determined by similar 2,6-DMP activity measurement where laccase activity was subtracted and $\mathrm{MnSO}_{4}$ and $\mathrm{H}_{2} \mathrm{O}_{2}$ were used in malonate buffer.

GPC. The molecular weight distributions of fungal-treated and untreated lignin were measured by using Agilent 1260 Infinity LC-UV system. Solid samples of 1-2.4 mg were mixed with $\mathrm{DMF} / \mathrm{LiBr}\left(1 \mathrm{~g} \mathrm{~L}^{-1}\right)$ eluent to obtain $1 \mathrm{mg} \mathrm{mL}^{-1}$ final concentration. Samples were dissolved by mixing overnight and filtered using $0.2 \mu \mathrm{m}$ Acrodisc GHP Membrane HPLC filters (Waters). Separation was performed using Acquity APC XT 2002.5 and $451.7 \mu \mathrm{m}$ columns (Waters) with $0.5 \mathrm{~mL}$ $\mathrm{min}^{-1} \mathrm{DMF} / \mathrm{LiBr}$ elution at $50{ }^{\circ} \mathrm{C}$. A UV detector was run using $280 \mathrm{~nm}$ wavelength. Polystyrene standards (Scientific Polymer Products and Fluka Analytical) were used for the calibration of the molar mass. Data was processed using Agilent 1260 Infinity software to gain number-average molecular weight $\left(M_{\mathrm{n}}\right)$, weight-average molecular weight $\left(M_{\mathrm{w}}\right)$, and polydispersity index (PDI, $\left.M_{\mathrm{w}} / M_{\mathrm{n}}\right)$.

Py-GC-MS. Measurements were performed using Pyrolab2000 pyrolyzer connected to Bruker Scion SQ 456 GCMS. The pyrolysis chamber temperature was kept at $150{ }^{\circ} \mathrm{C}$, and samples were pyrolyzed isothermally by heating the platinum filament in $8 \mathrm{~ms}$ to $580{ }^{\circ} \mathrm{C}$ and keeping the temperature elevated for $2 \mathrm{~s}$ before rapid cooling of the filament. Helium was used as a carrier gas at the flow rate of 1 $\mathrm{mL} \min ^{-1}$. The injector temperature was $250{ }^{\circ} \mathrm{C}$, and $1: 2$ split ratio was used. Pyrolysis products were separated in an Agilent DB-5MS UI ((5\%-phenyl)-methylpolysiloxane, $30 \mathrm{~m} \times 0.250$ $\mathrm{mm} \times 0.25 \mu \mathrm{m}$ film) capillary column. The column oven temperature was kept at $50{ }^{\circ} \mathrm{C}$ for $2 \mathrm{~min}$, after which the temperature was increased at $10{ }^{\circ} \mathrm{C} \mathrm{min}^{-1}$ rate to $280{ }^{\circ} \mathrm{C}$, resulting in a $25 \mathrm{~min}$ overall run time. The ion source temperature was $250{ }^{\circ} \mathrm{C}$ with electron ionization of $70 \mathrm{eV}$. The MS scan range was $40-400 \mathrm{~m} / z$. Twenty-five peaks were detected from the total ion count chromatograms between 3.3 and 14.3 min retention times, and 22 of the compounds could be identified by comparing to standard sample runs, to the National Institute of Standards and Technology (NIST) library, and to the literature. ${ }^{48,51-55}$

HSQC NMR. Samples were dissolved in DMSO- $d_{6}(65 \mathrm{mg}$ in $0.7 \mathrm{~mL}$ ) by stirring overnight. The $2 \mathrm{D}{ }^{1} \mathrm{H}-{ }^{13} \mathrm{C}$ HSQC spectra were recorded on a Bruker Avance NEO $400 \mathrm{MHz}$ spectrometer equipped with a Bruker $5 \mathrm{~mm}$ direct detection PA BBO BBF H-D-05-Z SP SmartProbe using the multiplicityedited HSQCEDETGPSISP pulse sequence at $23{ }^{\circ} \mathrm{C}$. The spectral width in F2 $\left({ }^{1} \mathrm{H}\right)$ dimension was 13.15 ppm with 2048 data points, and the spectral width in $\mathrm{F} 1\left({ }^{13} \mathrm{C}\right)$ dimension was 165 ppm with 256 data points. For each spectrum, 64 scans were measured using $1.5 \mathrm{~s}$ relaxation delay, which resulted in 7 h, $51 \mathrm{~min}$, and $37 \mathrm{~s}$ measurement time. The spectra were processed with Bruker TopSpin 4.0.2 software. The solvent signal $(2.5 / 39.52 \mathrm{ppm})$ was used in the calibration, and the HSQC cross-signals were assigned according to the literature. ${ }^{35,56-62}$
${ }^{13} \mathrm{C}$ NMR. The spectra were recorded on a Bruker Avance III $500 \mathrm{MHz}$ equipped with a Bruker $5 \mathrm{~mm}$ BBO probe. Lignin samples solvated in DMSO- $d_{6}$ were measured using the zgpg30 pulse program with a $90^{\circ}$ pulse angle at $60{ }^{\circ} \mathrm{C}$. A total of 68,608 scans were run using $1.188 \mathrm{~s}$ acquisition time and $2 \mathrm{~s}$ relaxation delay, which resulted in 2 days, $13 \mathrm{~h}, 57 \mathrm{~min}$, and 57 s experiment time for each sample. The spectra were processed with Bruker TopSpin 4.0.2 software. The solvent signal (39.52 $\mathrm{ppm}$ ) was used in the calibration, and signals were assigned according to the literature. ${ }^{35,63}$

Quantitative ${ }^{31} \mathrm{P}$ NMR. Measurements were performed as reported previously. ${ }^{64,65}$ Well-dried $40 \mathrm{mg}$ lignin samples were mixed with $0.6 \mathrm{~mL}$ of $1.6: 1 \mathrm{Pyr} / \mathrm{CDCl}_{3}$ and stirred overnight, followed by addition of $0.2 \mathrm{~mL}$ of internal standard $(\mathrm{N}$ hydroxy-5-norbornene-2,3-dicarboxylic acid imide; $9.27 \mathrm{mg}$ $\mathrm{mL}^{-1}$ in $\mathrm{CDCl}_{3}$ ), $50 \mu \mathrm{L}$ of chromium(III) acetylacetonate, and $150 \mu \mathrm{L}$ of in-house synthetized ${ }^{31} \mathrm{P}$ reagent ${ }^{66}$ (2-chloro-4,4,5,5tetramethyl-1,3,2-dioxaphospholane). All samples were measured right after the addition of ${ }^{31} \mathrm{P}$ reagent. The quantitative ${ }^{31} \mathrm{P}$ NMR measurements were performed using a Bruker Avance III $500 \mathrm{MHz}$ equipped with a Bruker $5 \mathrm{~mm}$ BBO probe. A total of 200 scans were recorded at $23{ }^{\circ} \mathrm{C}$ using Bruker's standard pulse program zg with a $90^{\circ}$ pulse angle, $1.625 \mathrm{~s}$ acquisition time, and $5 \mathrm{~s}$ relaxation delay. All spectra were calibrated using a $\mathrm{H}_{2} \mathrm{O}$ signal at $132.2 \mathrm{ppm}$ as a reference. Gained data was processed with Bruker TopSpin 4.0.2 software. The following integration regions were used to determine the abundance of different $\mathrm{OH}$ groups: internal standard, 152.4-151.5 ppm; aliphatic OH, 149-145 ppm; condensed phenolic OH, 145-140.4 ppm; noncondensed phenolic OH, 140.4-137.2 ppm; COOH, 134-136 ppm. These integration regions are suitable for softwood lignins, which do not contain syringyl $\mathrm{OH}$ groups.

TGA. Thermogravimetry was used to study thermal degradation of samples. A Mettler Toledo TGA/SDTA851e/ SF/1100 with Julabo cooler model ED was used. Onset values were determined using STARe software version 9.01. Raw data was imported to MS Excel from which TGA curves were constructed. Sample sizes were $9-12 \mathrm{mg}$ in reusable $70 \mu \mathrm{L}$ alumina crucibles with lids. The temperature program used a ramp speed of $10{ }^{\circ} \mathrm{C} \mathrm{min}{ }^{-1}$ and nitrogen flow of $50 \mathrm{~mL} \mathrm{~min}^{-1}$. An annealing cycle was used for all samples as pretreatment and consisted of the following segments: ramp to $105{ }^{\circ} \mathrm{C}$, isothermal $20 \mathrm{~min}$, ramp to $60{ }^{\circ} \mathrm{C}$, and isothermal $2 \mathrm{~min}$. It was followed by the measurement cycle, which was simply ramp to $800{ }^{\circ} \mathrm{C}$. The onset temperature, thermal stability, and residual mass were analyzed. Precursor fiber samples were molded into pans by threading a needle, spinning 8-12 turns around the needle, pulling the knot through the line, tightening the knot, and cutting the knot into a cylindrical structure.

DSC. Glass transition temperatures $\left(T_{\mathrm{g}}\right.$ 's) of samples were determined using a TA Instruments Q200 DSC coupled to a RCS90 cooling system. Raw data was exported from TA Universal Analysis 2000 software and imported to MS Excel from which DSC curves were drawn. Sample sizes were 7-10 $\mathrm{mg}$ in aluminum hermetic pans and lids with two self-drilled holes (diameter, $0.28 \mathrm{~mm}$ ). The temperature program induced a ramp speed of $10{ }^{\circ} \mathrm{C} \mathrm{min}^{-1}$ and nitrogen flow of $50 \mathrm{~mL}$ $\mathrm{min}^{-1}$. All samples were pretreated with an annealing cycle: ramp to $105{ }^{\circ} \mathrm{C}$ and isothermal for $20 \mathrm{~min}$. This was followed by heating cycles up to $190{ }^{\circ} \mathrm{C}$ for lignins and $260{ }^{\circ} \mathrm{C}$ for precursor fibers with starting temperatures ranging between -50 and $+30{ }^{\circ} \mathrm{C}$. Heating cycle ramps were the dominant 
source of $T_{\mathrm{g}}$ for samples and were recorded on the second heating cycle after first erasing the thermal history on the first heating cycle. The $T_{\mathrm{g}}$ for lignin samples was defined as one-half the change in heat capacity occurring over the transition.

Precursor Fibers. The preparation of ionic liquid (IL) and dope and the fiber spinning were done with the Ioncell process and performed according to previously published methods, with only minor modifications. ${ }^{38,67}$ The 1,5diazabicyclo[4.3.0] non-5-ene-1-ium acetate ([DBNH]OAc) IL was always prepared on the same day as the dope preparation. Cellulose and lignin were dissolved in the IL in a kneader at $80{ }^{\circ} \mathrm{C}$ for $90 \mathrm{~min}$. The applied pressure was $10 \pm 2$ mbar, and the mixing speed was $30 \mathrm{rpm}$. The dissolved cellulose-lignin mixtures (dopes) were filtered using a filter press with a filter pore size of $5 \mu \mathrm{m}$. The filtered dope was spun using a piston spinning unit (Fourné Polymertechnik, Germany). A spinneret with 400 holes, a capillary diameter of $100 \mu \mathrm{m}$, and L/D 0.2 was used. The extrusion rate was 5.5 $\mathrm{mL} \min ^{-1}$ and the dope temperature was $75 \pm 4{ }^{\circ} \mathrm{C}$. After spinning, the fibers were washed with tap water $(10 \pm 0.25$ min; water temperature, $68 \pm 3{ }^{\circ} \mathrm{C}$; air drying, $80{ }^{\circ} \mathrm{C}$ ) using a custom-made washing machine.

Carbohydrate and Lignin Analysis. The sample preparation for carbohydrate and lignin analyses were made according to NREL/TP-510-42618, and the samples were analyzed using an ICS-3000 HPAEC-PAD with a Dionex CarboPac PA20 column (Thermo Fisher Scientific, USA). The acid-soluble lignin (ASL) was determined by using a Shimadzu UV 2550 spectrophotometer at $205 \mathrm{~nm}$.

SEM. For cross-section imaging, the precursor fibers were first frozen in water solution, then submerged into liquid nitrogen for at least $5 \mathrm{~min}$, and finally fractured by hitting the cooled ice pieces against a sharp edge. Gained cryo-fractured fibers were dried in a hood for several days and then attached to double-angled $90^{\circ}$ chamfer specimen stubs using two-sided tape. Samples were gold-coated without spinning, and images were taken with Hitachi S-4800 equipment at $5 \mathrm{kV}$ operating voltage.

Mechanical Testing. The mechanical properties of the precursor fibers were measured using a Favigraph single-fiber tester (Textechno H. Stein GmbH \& Co. KG, Germany) according to the standard SFS-EN 5079 with only minor modifications. The precursor fibers were conditioned in $20 \pm 2$ ${ }^{\circ} \mathrm{C}$ and $65 \pm 2 \% \mathrm{RH}$ overnight prior to the mechanical testing. The following conditions were used for the testing: load cell, $20 \mathrm{cN}$; gauge length, $20 \mathrm{~mm}$; test speed, $20 \mathrm{~mm} \mathrm{~min}^{-1}$. For each sample, 20 fibers were measured.

\section{ASSOCIATED CONTENT}

\section{(s) Supporting Information}

The Supporting Information is available free of charge at https://pubs.acs.org/doi/10.1021/acsomega.0c00142.

Py-GC-MS results, HSQC NMR, TGA and DTG results of kraft lignin and tyndallized kraft lignin, and integrated peaks from the HSQC spectra (PDF)

\section{AUTHOR INFORMATION}

\section{Corresponding Author}

Joona Mikkilä - Department of Microbiology and Department of Chemistry, University of Helsinki, Helsinki FI-00014 Helsinki, Finland; 이이이.org/0000-0002-8987-3806; Phone: +358504413086; Email: joona.mikkila@helsinki.fi

\section{Authors}

Mikaela Trogen - Department of Bioproducts and Biosystems, Aalto University, Espoo FI-00076 Aalto, Finland

Klaus A. Y. Koivu - Department of Chemistry, University of Helsinki, Helsinki FI-00014 Helsinki, Finland

Jussi Kontro - Department of Chemistry, University of Helsinki, Helsinki FI-00014 Helsinki, Finland

Jaana Kuuskeri - Department of Microbiology, University of Helsinki, Helsinki FI-00014 Helsinki, Finland

Riku Maltari - Department of Microbiology and Department of Chemistry, University of Helsinki, Helsinki FI-00014 Helsinki, Finland

Zane Dekere - Department of Microbiology, University of Helsinki, Helsinki FI-00014 Helsinki, Finland

Marianna Kemell - Department of Chemistry, University of Helsinki, Helsinki FI-00014 Helsinki, Finland; (ㄷ) orcid.org/ 0000-0002-3583-2064

Miia R. Mäkelä - Department of Microbiology, University of Helsinki, Helsinki FI-00014 Helsinki, Finland; 이이.org/ 0000-0003-0771-2329

Paula A. Nousiainen - Department of Chemistry, University of Helsinki, Helsinki FI-00014 Helsinki, Finland; 자이.org/ 0000-0002-7089-1158

Michael Hummel - Department of Bioproducts and Biosystems, Aalto University, Espoo FI-00076 Aalto, Finland

Jussi Sipilä - Department of Chemistry, University of Helsinki, Helsinki FI-00014 Helsinki, Finland; 이이. ord.org/0000-00022957-1443

Kristiina Hildén - Department of Microbiology, University of Helsinki, Helsinki FI-00014 Helsinki, Finland; 이이.org/ 0000-0002-0126-8186

Complete contact information is available at:

https://pubs.acs.org/10.1021/acsomega.0c00142

\section{Notes}

The authors declare no competing financial interest.

\section{ACKNOWLEDGMENTS}

J.M., J. Kuuskeri, Z.D., R.M., and K.H. acknowledge the support through the Novo Nordisk Foundation grant NNF160C0021704 "Production of high quality lignin from technical lignins by enzymatic catalysis" (LIGNICAT). P.N. acknowledges the support through EU Horizon 2020 (project no. 720918). J. Kontro and M.R.M. acknowledge the support through Academy of Finland project nos. 298882 and 308284, respectively. The Ioncell precursor fibers were produced as part of the project "Unlocking the Entire Wood Matrix for the Next Generation of Carbon Fibres" (WoCaFi). This project has received funding from the European Research Council (ERC) under the European Union's Horizon 2020 research and innovation program (grant no. 715788). Stora Enso is acknowledged for providing the Lineo kraft lignin.

\section{REFERENCES}

(1) Ragauskas, A. J.; Beckham, G. T.; Biddy, M. J.; Chandra, R.; Chen, F.; Davis, M. F.; Davison, B. H.; Dixon, R. A.; Gilna, P.; Keller, M.; et al. Lignin Valorization: Improving Lignin Processing in the Biorefinery. Science 2014, 344, 1246843.

(2) Fache, M.; Boutevin, B.; Caillol, S. Vanillin Production from Lignin and Its Use as a Renewable Chemical. ACS Sustainable Chem. Eng. 2016, 4, 35-46.

(3) Sjöström, E. Wood Chemistry : Fundamentals and Applications; 2nd Ed.; Academic Press Inc.: San Diego, 1993. 
(4) Kai, D.; Tan, M. J.; Chee, P. L.; Chua, Y. K.; Yap, Y. L.; Loh, X. J. Towards Lignin-Based Functional Materials in a Sustainable World. Green Chem. 2016, 18, 1175-1200.

(5) Geng, X.; Zhang, Y.; Jiao, L.; Yang, L.; Hamel, J.; Giummarella, N.; Henriksson, G.; Zhang, L.; Zhu, H. Bioinspired Ultrastable Lignin Cathode via Graphene Reconfiguration for Energy Storage. ACS Sustainable Chem. Eng. 2017, 5, 3553-3561.

(6) Espinoza-Acosta, J. L.; Torres-Chávez, P. I.; Olmedo-Martínez, J. L.; Vega-Rios, A.; Flores-Gallardo, S.; Zaragoza-Contreras, E. A. Lignin in Storage and Renewable Energy Applications: A Review. J. Energy Chem. 2018, 27, 1422-1438.

(7) Yang, J.; Wang, Y.; Luo, J.; Chen, L. Facile Preparation of SelfStanding Hierarchical Porous Nitrogen-Doped Carbon Fibers for Supercapacitors from Plant Protein-Lignin Electrospun Fibers. ACS Omega 2018, 3, 4647-4656.

(8) Kleinhans, H.; Salmén, L. Development of Lignin Carbon Fibers: Evaluation of the Carbonization Process. J. Appl. Polym. Sci. 2016, 133, 43965.

(9) Culebras, M.; Beaucamp, A.; Wang, Y.; Clauss, M. M.; Frank, E.; Collins, M. N. Biobased Structurally Compatible Polymer Blends Based on Lignin and Thermoplastic Elastomer Polyurethane as Carbon Fiber Precursors. ACS Sustainable Chem. Eng. 2018, 6, 88168825.

(10) Cho, M.; Ko, F. K.; Renneckar, S. Impact of Thermal Oxidative Stabilization on the Performance of Lignin-Based Carbon Nanofiber Mats. ACS Omega 2019, 4, 5345-5355.

(11) Figueiredo, P.; Lintinen, K.; Kiriazis, A.; Hynninen, V.; Liu, Z.; Bauleth-Ramos, T.; Rahikkala, A.; Correia, A.; Kohout, T.; Sarmento, B.; et al. In Vitro Evaluation of Biodegradable Lignin-Based Nanoparticles for Drug Delivery and Enhanced Antiproliferation Effect in Cancer Cells. Biomaterials 2017, 121, 97-108.

(12) Fang, W.; Yang, S.; Wang, X.-L.; Yuan, T.-Q.; Sun, R.-C. Manufacture and Application of Lignin-Based Carbon Fibers (LCFs) and Lignin-Based Carbon Nanofibers (LCNFs). Green Chem. 2017, 19, 1794-1827.

(13) Baker, F. S. Low Cost Carbon Fiber from Renewable Resources; Oral Presentation - U.S. Department of Energy: Washington, 2010, June.

(14) Mainka, H.; Täger, O.; Körner, E.; Hilfert, L.; Busse, S.; Edelmann, F. T.; Herrmann, A. S. Lignin - An Alternative Precursor for Sustainable and Cost-Effective Automotive Carbon Fiber. J. Mater. Res. Technol. 2015, 4, 283-296.

(15) European Union Regulation (EC) No 443/2009: Reducing CO2 Emissions from Passenger Cars; European Union, 2009.

(16) Navarro-Suárez, A. M.; Carretero-González, J.; Casado, N.; Mecerreyes, D.; Rojo, T.; Castillo-Martínez, E. Hybrid Biopolymer Electrodes for Lithium- and Sodium-Ion Batteries in Organic Electrolytes. Sustain. Energy Fuels 2018, 2, 836-842.

(17) Culebras, M.; Geaney, H.; Beaucamp, A.; Upadhyaya, P.; Dalton, E.; Ryan, K. M.; Collins, M. N. Bio-Derived Carbon Nanofibres from Lignin as High-Performance Li-Ion Anode Materials. ChemSusChem 2019, 12, 4516-4521.

(18) Norberg, I.; Nordström, Y.; Drougge, R.; Gellerstedt, G.; Sjöholm, E. A New Method for Stabilizing Softwood Kraft Lignin Fibers for Carbon Fiber Production. J. Appl. Polym. Sci. 2013, 128, 3824-3830.

(19) Zhang, M.; Ogale, A. A. Carbon Fibers from Dry-Spinning of Acetylated Softwood Kraft Lignin. Carbon N. Y. 2014, 69, 626-629.

(20) Liu, H.; Dai, Z.; Cao, Q.; Shi, X.; Wang, X.; Li, H.; Han, Y.; Li, Y.; Zhou, J. Lignin/Polyacrylonitrile Carbon Fibers: The Effect of Fractionation and Purification on Properties of Derived Carbon Fibers. ACS Sustainable Chem. Eng. 2018, 6, 8554-8562.

(21) Li, Q.; Naik, M. T.; Lin, H.-S.; Hu, C.; Serem, W. K.; Liu, L.; Karki, P.; Zhou, F.; Yuan, J. S. Tuning Hydroxyl Groups for Quality Carbon Fiber of Lignin. Carbon N. Y. 2018, 139, 500-511.

(22) Jin, J.; Ding, J.; Klett, A.; Thies, M. C.; Ogale, A. A. Carbon Fibers Derived from Fractionated-Solvated Lignin Precursors for Enhanced Mechanical Performance. ACS Sustainable Chem. Eng. 2018, 6, 14135-14142.
(23) Li, Q.; Xie, S.; Serem, W. K.; Naik, M. T.; Liu, L.; Yuan, J. S. Quality Carbon Fibers from Fractionated Lignin. Green Chem. 2017, $19,1628-1634$.

(24) Sagues, W. J.; Jain, A.; Brown, D.; Aggarwal, S.; Suarez, A.; Kollman, M.; Parka, S.; Argyropoulos, D. S. Are Lignin-Derived Carbon Fibers Graphitic Enough? Green Chem. 2019, 21, 4253-4265.

(25) Nordström, Y.; Norberg, I.; Sjöholm, E.; Drougge, R. A New Softening Agent for Melt Spinning of Softwood Kraft Lignin. J. Appl. Polym. Sci. 2013, 129, 1274-1279.

(26) Salmén, L.; Bergnor, E.; Olsson, A.-M.; Åkerström, M.; Uhlin, A. Extrusion of Softwood Kraft Lignins as Precursors for Carbon Fibres. BioResources 2015, 10, 7544-7554.

(27) Byrne, N.; De Silva, R.; Ma, Y.; Sixta, H.; Hummel, M. Enhanced Stabilization of Cellulose-Lignin Hybrid Filaments for Carbon Fiber Production. Cellulose 2018, 25, 723-733.

(28) Bugg, T. D. H.; Rahmanpour, R. Enzymatic Conversion of Lignin into Renewable Chemicals. Curr. Opin. Chem. Biol. 2015, 29, $10-17$.

(29) Maijala, P.; Mattinen, M.-L.; Nousiainen, P.; Kontro, J.; Asikkala, J.; Sipilä, J.; Viikari, L. Action of Fungal Laccases on Lignin Model Compounds in Organic Solvents. J. Mol. Catal. B: Enzym. 2012, 76, 59-67.

(30) Janusz, G.; Kucharzyk, K. H.; Pawlik, A.; Staszczak, M.; Paszczynski, A. J. Fungal Laccase, Manganese Peroxidase and Lignin Peroxidase: Gene Expression and Regulation. Enzyme Microb. Technol. 2013, 52, 1-12.

(31) Hildén, K.; Mäkelä, M. R.; Lundell, T.; Kuuskeri, J.; Chernykh, A.; Golovleva, L.; Archer, D. B.; Hatakka, A. Heterologous Expression and Structural Characterization of Two Low PH Laccases from a Biopulping White-Rot Fungus Physisporinus rivulosus. Appl. Microbiol. Biotechnol. 2013, 97, 1589-1599.

(32) Salvachúa, D.; Katahira, R.; Cleveland, N. S.; Khanna, P.; Resch, M. G.; Black, B. A.; Purvine, S. O.; Zink, E. M.; Prieto, A.; Martínez, M. J.; et al. Lignin Depolymerization by Fungal Secretomes and a Microbial Sink. Green Chem. 2016, 18, 6046-6062.

(33) Nousiainen, P.; Kontro, J.; Manner, H.; Hatakka, A.; Sipilä, J. Phenolic Mediators Enhance the Manganese Peroxidase Catalyzed Oxidation of Recalcitrant Lignin Model Compounds and Synthetic Lignin. Fungal Genet. Biol. 2014, 72, 137-149.

(34) Hakala, T. K.; Lundell, T.; Galkin, S.; Maijala, P.; Kalkkinen, N.; Hatakka, A. Manganese Peroxidases, Laccases and Oxalic Acid from the Selective White-Rot Fungus Physisporinus rivulosus Grown on Spruce Wood Chips. Enzyme Microb. Technol. 2005, 36, 461-468.

(35) Crestini, C.; Lange, H.; Sette, M.; Argyropoulos, D. S. On The Structure Of Softwood Kraft Lignin. Green Chem. 2017, 19, 41044121.

(36) Hong, C.-Y.; Ryu, S.-H.; Jeong, H.; Lee, S.-S.; Kim, M.; Choi, I.-G. Phanerochaete Chrysosporium Multienzyme Catabolic System for in Vivo Modification of Synthetic Lignin to Succinic Acid. ACS Chem. Biol. 2017, 12, 1749-1759.

(37) Zhao, C.; Xie, S.; Pu, Y.; Zhang, R.; Huang, F.; Ragauskas, A. J.; Yuan, J. S. Synergistic Enzymatic and Microbial Lignin Conversion. Green Chem. 2016, 18, 1306-1312.

(38) Ma, Y.; Asaadi, S.; Johansson, L.-S.; Ahvenainen, P.; Reza, M.; Alekhina, M.; Rautkari, L.; Michud, A.; Hauru, L.; Hummel, M.; et al. High-Strength Composite Fibers from Cellulose-Lignin Blends Regenerated from Ionic Liquid Solution. ChemSusChem 2015, 8, 4030-4039.

(39) Duong, L. D.; Nam, G.-Y.; Oh, J.-S.; Park, I.-K.; Luong, N. D.; Yoon, H.-K.; Lee, S.-H.; Lee, Y.; Yun, J.-H.; Lee, C.-G.; et al. High Molecular-Weight Thermoplastic Polymerization of Kraft Lignin Macromers with Diisocyanate. BioResources 2014, 9, 2359-2371.

(40) Seo, J. H.; Jeong, H.; Lee, H. W.; Choi, C. S.; Bae, J. H.; Lee, S. M.; Kim, Y. S. Characterization of Solvent-Fractionated Lignins from Woody Biomass Treated via Supercritical Water Oxidation. Bioresour. Technol 2019, 275, 368-374.

(41) Culebras, M.; Sanchis, M. J.; Beaucamp, A.; Carsí, M.; Kandola, B. K.; Horrocks, A. R.; Panzetti, G.; Birkinshaw, C.; Collins, M. N. Understanding the Thermal and Dielectric Response of Organosolv 
and Modified Kraft Lignin as a Carbon Fibre Precursor. Green Chem. 2018, 20, 4461-4472.

(42) Fink, H.-P.; Weigel, P.; Purz, H. J.; Ganster, J. Structure Formation of Regenerated Cellulose Materials from NMMOSolutions. Prog. Polym. Sci. 2001, 26, 1473-1524.

(43) Röder, T.; Moosbauer, J.; Kliba, G.; Schlader, S.; Zuckerstätter, G.; Sixta, H. Comparative Characterisation of Man-Made Regenerated Cellulose Fibres. Lenzinger Berichte 2009, 87, 98-105.

(44) Nishiyama, Y.; Asaadi, S.; Ahvenainen, P.; Sixta, H. WaterInduced Crystallization and Nano-Scale Spinodal Decomposition of Cellulose in NMMO and Ionic Liquid Dope. Cellulose 2019, 26, 281289.

(45) Ma, Y.; Hummel, M.; Määttänen, M.; Särkilahti, A.; Harlin, A.; Sixta, H. Upcycling of Waste Paper and Cardboard to Textiles. Green Chem. 2016, 18, 858-866.

(46) Frank, E.; Steudle, L. M.; Ingildeev, D.; Spörl, J. M.; Buchmeiser, M. R. Carbon Fibers: Precursor Systems, Processing, Structure, and Properties. Angew. Chem., Int. Ed. 2014, 53, 52625298.

(47) Hatakka, A. I.; Uusi-Rauva, A. K. Degradation of 14C-Labelled Poplar Wood Lignin by Selected White-Rot Fungi. Eur. J. Appl. Microbiol. Biotechnol. 1983, 17, 235-242.

(48) Brzonova, I.; Asina, F.; Andrianova, A. A.; Kubátová, A.; Smoliakova, I. P.; Kozliak, E. I.; Ji, Y. Fungal Biotransformation of Insoluble Kraft Lignin into a Water Soluble Polymer. Ind. Eng. Chem. Res. 2017, 56, 6103-6113.

(49) Miettinen, O.; Riley, R.; Barry, K.; Cullen, D.; de Vries, R. P.; Hainaut, M.; Hatakka, A.; Henrissat, B.; Hildén, K.; Kuo, R.; et al. Draft Genome Sequence of the White-Rot Fungus Obba rivulosa 3A2. Genome Announc. 2016, 4, e00976-e00916.

(50) Slomczynski, D.; Nakas, J. P.; Tanenbaum, S. W. Production and Characterization of Laccase from Botrytis Cinerea 61-34. Appl. Environ. Microbiol. 1995, 61, 907-912.

(51) Kuuskeri, J.; Häkkinen, M.; Laine, P.; Smolander, O.-P.; Tamene, F.; Miettinen, S.; Nousiainen, P.; Kemell, M.; Auvinen, P.; Lundell, T. Time-Scale Dynamics of Proteome and Transcriptome of the White-Rot Fungus Phlebia radiata: Growth on Spruce Wood and Decay Effect on Lignocellulose. Biotechnol. Biofuels 2016, 9, 192.

(52) Brebu, M.; Tamminen, T.; Spiridon, I. Thermal Degradation of Various Lignins by TG-MS/FTIR and Py-GC-MS. J. Anal. Appl. Pyrolysis 2013, 104, 531-539.

(53) Zhang, J. J.; Jiang, X. Y.; Ye, X. N.; Chen, L.; Lu, Q.; Wang, X. H.; Dong, C. Q. Pyrolysis Mechanism of a $\beta$-O-4 Type Lignin Dimer Model Compound. J. Therm. Anal. Calorim. 2016, 123, 501-510.

(54) Ohra-Aho, T.; Niemi, P.; Aura, A. M.; Orlandi, M.; Poutanen, K.; Buchert, J.; Tamminen, T. Structure of Brewer's Spent Grain Lignin and Its Interactions with Gut Microbiota in Vitro. J. Agric. Food Chem. 2016, 64, 812-820.

(55) Bai, X.; Kim, K. H.; Brown, R. C.; Dalluge, E.; Hutchinson, C.; Lee, Y. J.; Dalluge, D. Formation of Phenolic Oligomers during Fast Pyrolysis of Lignin. Fuel 2014, 128, 170-179.

(56) Constant, S.; Wienk, H. L. J.; Frissen, A. E.; de Peinder, P.; Boelens, R.; van Es, D. S.; Grisel, R. J. H.; Weckhuysen, B. M.; Huijgen, W. J. J.; Gosselink, R. J. A.; et al. New Insights into the Structure and Composition of Technical Lignins: A Comparative Characterisation Study. Green Chem. 2016, 18, 2651-2665.

(57) Rahimi, A.; Azarpira, A.; Kim, H.; Ralph, J.; Stahl, S. S. Chemoselective Metal-Free Aerobic Alcohol Oxidation in Lignin. J. Am. Chem. Soc. 2013, 135, 6415-6418.

(58) Rencoret, J.; Kim, H.; Evaristo, A. B.; Gutiérrez, A.; Ralph, J.; Del Río, J. C. Variability in Lignin Composition and Structure in Cell Walls of Different Parts of Macaúba (Acrocomia Aculeata) Palm Fruit. J. Agric. Food Chem. 2018, 66, 138-153.

(59) Lancefield, C. S.; Wienk, H. L. J.; Boelens, R.; Weckhuysen, B. M.; Bruijnincx, P. C. A. Identification of a Diagnostic Structural Motif Reveals a New Reaction Intermediate and Condensation Pathway in Kraft Lignin Formation. Chem. Sci 2018, 9, 6348-6360.

(60) McClelland, D. J.; Motagamwala, A. H.; Li, Y.; Rover, M. R.; Wittrig, A. M.; Wu, C.; Buchanan, J. S.; Brown, R. C.; Ralph, J.;
Dumesic, J. A.; et al. Functionality and Molecular Weight Distribution of Red Oak Lignin before and after Pyrolysis and Hydrogenation. Green Chem. 2017, 19, 1378-1389.

(61) Daly, P.; Casado López, S.; Peng, M.; Lancefield, C. S.; Purvine, S. O.; Kim, Y.-M.; Zink, E. M.; Dohnalkova, A.; Singan, V. R.; Lipzen, A.; et al. Dichomitus Squalens Partially Tailors Its Molecular Responses to the Composition of Solid Wood. Environ. Microbiol. 2018, 20, 4141-4156.

(62) Ralph, J.; Landucci, L. L. NMR of Lignins. In Lignin and Lignans: Advances in Chemistry; Heitner, C., Cimmel, D. R., Schmidt, J. A., Eds.; CRC Press (Taylor \& Francis Group): Boca Raton, 2010; 137-243.

(63) Kringstad, K. P.; Mörck, R. 13C-NMR Spectra of Kraft Lignins. Holzforschung 1983, 37, 237-244.

(64) Koivu, K. A. Y.; Sadeghifar, H.; Nousiainen, P. A.; Argyropoulos, D. S.; Sipilä, J. Effect of Fatty Acid Esterification on the Thermal Properties of Softwood Kraft Lignin. ACS Sustainable Chem. Eng. 2016, 4, 5238-5247.

(65) Granata, A.; Argyropoulos, D. S. 2-Chloro-4,4,5,5-Tetramethyl1,3,2-Dioxaphospholane, a Reagent for the Accurate Determination of the Uncondensed and Condensed Phenolic Moieties in Lignins. J. Agric. Food Chem. 1995, 43, 1538-1544.

(66) Zwierzak, A. Cyclic Organophosphorus Compounds. I. Synthesis and Infrared Spectral Studies of Cyclic Hydrogen Phosphites and Thiophosphites. Can. J. Chem. 1967, 45, 2501-2512.

(67) Hummel, M.; Michud, A.; Tanttu, M.; Asaadi, S.; Ma, Y.; Hauru, L. K. J.; Parviainen, A.; King, A. W. T.; Kilpeläinen, I.; Sixta, H. Ionic Liquids for the Production of Man-Made Cellulosic Fibers: Opportunities and Challenges. In Cellulose Chemistry and Properties: Fibers, Nanocelluloses and Advanced Materials. Advances in Polymer Science; Springer, Cham, 2015; Vol. 271, 133-168. 